\title{
BALANÇO HÍDRICO CLIMATOLÓGICO PARA ITAJUBÁ-MG: CENÁRIO ATUAL E PROJEÇÕES CLIMÁTICAS
}

\author{
ALVES, Alexandre Magalhães de Morais Ramos - alexandremmra@unifei.edu.br \\ Universidade Federal de Itajubá / UNIFEI
}

MARTINS, Fabrina Bolzan - fabrinabm@gmail.com

Universidade Federal de Itajubá / UNIFEI

REBOITA, Michelle Simões - mireboita@gmail.com
Universidade Federal de Itajubá / UNIFEI

\begin{abstract}
RESUMO: Projeções climáticas ao longo do século XXI têm indicado aumento da temperatura do ar, e irregularidades na precipitação no Estado de Minas Gerais (MG), os quais afetarão a evapotranspiração e, consequentemente, o balanço hídrico. Dessa forma, o objetivo desse trabalho foi verificar o impacto das mudanças climáticas no balanço hídrico climatológico (BHC) no município de Itajubá no período de 2021 a 2099 considerando o cenário de emissão Representative Concentration Pathway $(R C P) 8.5$ do Intergovernmental Panel on Climate Change (IPCC). Neste estudo, foram utilizadas projeções do modelo climático regional RegCM4 dirigido pelas saídas do modelo global HadGEM2-ES. O BHC foi calculado para o clima presente (1979 - 2005), futuro próximo (2021 - 2049) e futuro distante (2071 - 2099), considerando o método de Thornthwaite e Mather simplificado, em que considera como dado de entrada a climatologia mensal da temperatura média do ar e da precipitação. Projeta-se, para o final do século XXI, um aumento de aproximadamente $5^{\circ} \mathrm{C}$ na temperatura média do ar para Itajubá, além de um padrão heterogêneo de precipitação, com projeções de aumento nos meses de primavera e verão e redução nos meses de outono e inverno. Para o BHC é projetado aumento gradual na evapotranspiração real, chegando a $86 \mathrm{~mm}$ mês ${ }^{-1}$ nos meses de verão, e alteração na deficiência (DEF) e excedente hídrico (EXC). De maneira geral, é projetado um aumento da DEF e EXC nos meses de outono, inverno e verão, respectivamente. Tais alterações podem acarretar prejuízos para os principais cultivos de Itajubá, como o milho, a batata, o feijão e o café.
\end{abstract}

PALAVRAS-CHAVE: Disponibilidade Hídrica; Evapotranspiração; Climatologia; Mudanças Climáticas.

\section{CLIMATE WATER BALANCE FOR ITAJUBÁ-MG: CURRENT SCENARIO AND CLIMATE PROJECTIONS}

ABSTRACT: Climate projections throughout de 21st century have shown a notable rise in the air temperature and irregularities in the rain regime in the state of Minas Gerais (MG), which will affect the evapotranspiration pattern and hence the water balance. Thus, the main goal of this research was to acknowledge the impact of climate change on the climatological water balance (CWB) in Itajubá city, from 2021 to 2099, considering the Representative Concentration Pathway (RCP) 8.5 emission scenario of the Intergovernmental Panel on Climate Change (IPCC). For the study, it was used projections of the regional climate model RegCM4 driven by the outputs of the HadGEM2ES global model. The CWB was calculated for the present (1979 - 2005), near future (2021 - 2049) and distant future (2071 - 2099) climate, considering the simplified Thornthwaite and Mather method, where only the climatic means of air temperature and precipitation is required. It is projected, by the end of the 21st century, an increase of approximately $5^{\circ} \mathrm{C}$ in the average air temperature for Itajubá, in addition to a heterogeneous precipitation pattern, with projections of increase in the spring and summer months and reduction in the fall and winter months. For the CWB, a gradual increase in actual evapotranspiration is projected, reaching $86 \mathrm{~mm}$ month $^{-1}$ in the summer months, and changes in deficiency (DEF) and water surplus (EXC). In general, 
an increase in DEF is projected in the fall/winter months and an increase in EXC is projected in the summer months. Such changes can negatively impact the main crops cultivated in Itajubá, such as maize, potato, beans and coffee.

KEYWORDS: Water Availability; Evapotranspiration; Climatology, Climate Change.

\section{BALANCE HÍDRICO CLIMÁTICO PARA ITAJUBÁ-MG: ESCENARIO ACTUAL Y PROYECCIONES CLIMÁTICAS}

RESUMEN: Las proyecciones climáticas a lo largo del siglo XXI han indicado un aumento en la temperatura del aire e alteraciones en los patrones de precipitación en el estado de Minas Gerais (MG), lo que afectará la evapotranspiración y, en consecuencia, el equilibrio hídrico. El objetivo de este trabajo fue verificar el impacto de los cambios climáticos en el balance hídrico climatológico (BHC) en la ciudad de Itajubá desde 2021 hasta 2099 considerando el escenario de forzamiento radiativo (RCP) de 8.5. Fueron utilizados proyecciones del modelo climático regional RegCM4 impulsado por los resultados del modelo global HadGEM2-ES. El BHC se calculó para el clima presente (1979 - 2005), futuro próximo (2021 - 2049) y futuro lejano (2071 - 2099), considerando el método simplificado de Thornthwaite y Mather (1957), donde solo la climatología de la temperatura media del aire y precipitaciones. Se proyecta a finales del siglo XXI, un aumento $\sim 5^{\circ} \mathrm{C}$ en la temperatura del aire para Itajubá, además de un patrón de precipitación heterogéneo, con aumento en los meses de primavera y verano y reducción en los meses de otoño e invierno. Para BHC, se proyecta un aumento gradual en la evapotranspiración real, que alcanza los $86 \mathrm{~mm} \mathrm{mes}^{-1}$ en los meses de verano, y un cambio en la deficiencia (DEF) y el exceso de agua (EXC). En general, se proyecta un aumento en DEF y EXC en los meses de otoño / invierno y verano, respectivamente. Tales cambios no son beneficiosos ya que indican un aumento en eventos extremos, un aumento en el agua nociva y una disminución en el rendimiento de los principales cultivos de Itajubá, como maíz, papa, frijoles y café.

PALABRAS ClAVE: Disponibilidad de agua; Evapotranspiración; Climatología; Cambio Climático.

\section{INTRODUÇÃO}

Muitos sistemas naturais estão sendo afetados pelas mudanças climáticas regionais (RESENDE et al., 2019) e o impacto dessas mudanças será maior no setor agrícola e nos países em que a agricultura é a atividade econômica primária (PORFIRIO et al., 2018), como o Brasil (TAVARES et al., 2018; RESENDE et al., 2019). Nesse contexto, a região sudeste, especialmente o estado de Minas Gerais (MG), é considerado um dos mais vulneráveis às mudanças climáticas (DARELA-FILHO et al., 2016; NATIVIDADE et al., 2017; SANTOS et al., 2017; TAVARES et al., 2018) devido ao grande contingente populacional (21.040.662 habitantes IBGE, 2019) e à taxa de pobreza, principalmente, na região norte do estado $(3,01 \%$ taxa de pobreza extrema IPEA, 2012).

Estudos sobre mudanças climáticas e o impacto na disponibilidade hídrica podem ser realizados com saídas de modelos climáticos regionais e globais, sendo que os regionais possuem capacidade de representar as circulações de mesoescala, como as brisas, o que não ocorre com os modelos climáticos globais, cuja resolução horizontal é mais grosseira. Portanto, os modelos regionais podem representar melhor o clima de uma dada região (AMBRIZZI et al., 2018). Estudos de projeções climáticas realizados para Minas Gerais utilizando saídas de ambos os modelos apontam alterações nos campos médios sazonais de precipitação e temperatura do ar (SANTOS et al., 2017; MARTINS et 
al., 2018; REBOITA et al., 2018a; TAVARES et al., 2018). Especificamente, no decorrer do século XXI são projetados aumentos na temperatura do ar, chegando a $5^{\circ} \mathrm{C}$, e padrões heterogêneos de mudanças na precipitação (SANTOS et al., 2017; REBOITA et al., 2018a). Tais alterações poderão afetar conjuntamente a quantidade de água disponível no solo (MARTINS et al., 2019), os padrões de evapotranspiração e do balanço hídrico (ASSAD et al., 2004; TANASIJEVIC et al., 2014; MARTINS et al., 2018; SLAMA et al., 2019; RESENDE et al., 2019) que, por sua vez, irá prejudicar a sustentabilidade dos sistemas agrícolas, as áreas de aptidão aos cultivos (ASSAD et al., 2004; SANTOS et al., 2017) e, consequentemente, a população dependente do setor agrícola estará vulnerável a essas mudanças (PORFIRIO et al., 2018; MARTINS et al., 2019).

O município de Itajubá, localizado na região sul de Minas Gerais, é uma região vulnerável em termos de condições orográficas e hidrológicas, sendo afetado por enchentes e inundações que causam consequências negativas para a população que vive, principalmente, às margens do Rio Sapucaí e seus afluentes (BARBOSA et al., 2015; REBOITA et al., 2019). Além disso, o clima típico de monção, com estação chuvosa entre outubro e março e seca nos demais meses do ano (SILVA e REBOITA, 2013), faz com que Itajubá seja mais vulnerável aos eventos naturais extremos principalmente durante a estação chuvosa. No entanto, o clima do município associado ao tipo de solo com predomínio de Argissolo, Gleissolo e Cambissolo (Lima, 2012), favorece uma drenagem urbana deficitária em todos os meses do ano, sendo que na estação chuvosa há inundações e produção de água em excesso, que pode ser considerada água nociva quando comparado à produção de água útil. Enquanto nos meses de seca há diminuição do volume de recarga d'água dos rios, tendo como resultado a redução da disponibilidade hídrica no período de estiagem.

Com a redução da disponibilidade de água em Itajubá, dada pela falta de água de recarga ou produção de água excedente ou pela irregularidade de chuvas, o setor agrícola será um dos mais afetados, uma vez que é altamente dependente da demanda hídrica para a produção de culturas como a batata $\left(235 \mathrm{t} \mathrm{ano}^{-1}\right)$, milho $\left(209 \mathrm{t} \mathrm{ano}^{-1}\right)$, tomate $\left(200 \mathrm{t} \mathrm{ano}^{-1}\right)$, café $\left(35 \mathrm{t} \mathrm{ano}^{-1}\right) \mathrm{e}$ feijão ( $8 \mathrm{t} \mathrm{ano}^{-1}$ ) (SIDRA, 2019). Estudos que avaliem o impacto das mudanças climáticas na disponibilidade hídrica em municípios são escassos, principalmente os que utilizam modelos climáticos regionais. Além disso, não existem estudos dessa natureza em Itajubá o que constitui o principal objetivo desse estudo.

Portanto, o objetivo desse estudo foi verificar o impacto das mudanças climáticas no balanço hídrico climatológico no município de Itajubá baseado nas condições de clima presente (PP) (1979-2005), futuro próximo (FP) (20212049) e futuro distante (FD) (2071-2099) através de projeções climáticas oriundas do modelo regional RegCM4 (com $50 \mathrm{~km}$ de resolução horizontal), dirigido pelas saídas do modelo global HadGEM2-ES, considerando o cenário de emissão denominado Representative Concentration Pathways (RCP 8.5), que corresponde ao cenário com forçante radiativa mais intensa.

\section{MATERIAL E MÉTODOS}

\subsection{DADOS E LOCAL DE ESTUDO}

Foram utilizados dados diários de temperatura média do ar ( $\left.\mathrm{Tx} ;{ }^{\circ} \mathrm{C}\right) \mathrm{e}$ precipitação acumulada ( $\mathrm{P} ; \mathrm{mm} \mathrm{dia}^{-1}$ ) no clima presente (PP, 1979 - 2005) e futuro, denominado futuro próximo (FP, 2021 - 2049) e futuro distante (FD, 
2071 - 2099), considerando o cenário RCP8.5 (MOSS et al., 2010) do IPCC,

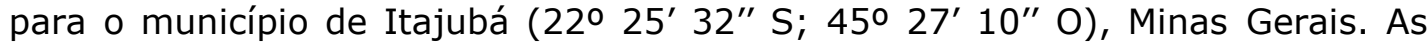
projeções foram oriundas do modelo climático regional RegCM4 que foi executado na fase 1 do Coordinated Regional Climate Downscaling Experiment (CORDEX: http://cordex.org) com $50 \mathrm{~km}$ de espaçamento de grade (GIORGI et al., 2009). O RegCM foi dirigido pelas projeções do modelo global HadGEM2-ES. $O$ estudo utilizou dados do modelo regional devido à melhor resolução horizontal quando comparado ao global, e parametrizações físicas mais adequadas para resolução de processos atmosféricos de mesoescala, possibilitando uma melhor representação do clima local (CUADRA; ROCHA, 2006; LLOPART et al., 2017; REBOITA et al., 2018). Apenas o cenário RCP8.5 foi utilizado, pois representa a forçante radiativa mais intensa (SANTOS et al., 2017; TAVARES et al., 2018).

Inicialmente, o período histórico das projeções (PP, 1979-2005) foi validado através de comparação com os dados do Climate Prediction Center (CPC: https://www.cpc.ncep.noaa.gov) - National Oceanic and Atmospheric Administration (NOAA) extraídos para o ponto de grade mais próximo de Itajubá (22.250 S, $45.75^{\circ}$ O). Os dados do CPC são construídos com base em dados medidos em estações meteorológicas (CHEN et al., 2008) e são atualizados diariamente (REBOITA et al., 2018). Ressalta-se que não foram utilizados dados de estação meteorológica na validação, uma vez que Itajubá não possuía estações meteorológicas operantes de acordo com os padrões da Organização Meteorológica Mundial (OMM) entre 1979-2005. Entretanto, preliminar ao emprego dos dados do CPC neste estudo, foi realizada uma comparação com os dados da estação meteorológica automática localizada no Campus da Universidade Federal de Itajubá - UNIFEI (latitude $22^{\circ} 26^{\prime}$ S, longitude $45^{\circ} 27^{\prime}$ W e altitude de $856 \mathrm{~m}$ ) pertencente ao Sistema de Meteorologia e Recursos Hídricos de Minas Gerais (SIMGE). Para esta comparação, foi utilizado o período entre 2000-2017 (Figura 1), uma vez que essa estação possui dados válidos somente neste período. Como as estatísticas calculadas apresentaram similaridades entre os conjuntos, o dado do CPC foi considerado adequado para este estudo climático. Ademais, a qualidade dos dados do CPC já tem sido avaliada em estudos prévios no estado de Minas Gerais e bem como têm sido empregado em estudos como o de Silva e Reboita (2013).

\subsection{OBTENÇÃO DA CLIMATOLOGIA E EVAPOTRANSPIRAÇÃO POTENCIAL}

Primeiramente obtiveram-se as médias mensais climatológicas da temperatura média do ar e precipitação acumulada no clima presente (PP) e futuro (FP e FD) seguindo as recomendações da Organização Meteorológica Mundial (WMO, 1989) estabelecidas no documento técnico OMM/TD-No 341:

$\bar{T}_{\text {med }}=\frac{\sum_{i=1}^{n} T_{x}}{n}$

$\bar{P}_{\text {med }}=\frac{\sum_{i=1}^{n} P_{x}}{n}$

em que: $\overline{\mathrm{T}}_{\text {med }}$ é a média climatológica da temperatura média do ar do i-ésimo mês $\left({ }^{\circ} \mathrm{C}\right), \mathrm{T}_{\mathrm{x}}$ é a temperatura média diária do ar $\left({ }^{\circ} \mathrm{C}\right)$ obtida pela média aritmética dos valores extremos diários (temperatura mínima e máxima do ar); $\overline{\mathrm{P}}_{\text {med }}$ é a média climatológica da precipitação mensal acumulada ( $\mathrm{mm}$ mês ${ }^{-1}$ ) e $\mathrm{P}_{\mathrm{x}}$ é a precipitação acumulada do i-ésimo mês $\left(\mathrm{mm}^{\mathrm{mês}}{ }^{-1}\right)$. 
Para o cálculo da evapotranspiração potencial (ETP) foi utilizado o método proposto por Thornthwaite (1948) devido à inexistência de dados observados e disponíveis para o local de estudo e por apresentar bons resultados para a região sul de Minas Gerais (SANTOS et al., 2017). Além disso, é o método de estimativa de ETP mais utilizado para balanços hídricos climatológicos (SENTELHAS et al., 2008), uma vez que fornece diretamente os valores climatológicos mensais da ETP.

$$
\begin{aligned}
& E T P_{x}=16 \cdot\left(10 \cdot \frac{\bar{T}_{\text {med }}}{I}\right)^{a} \text { quando } 0 \leq \bar{T}_{\text {med }} \leq 26,5 \\
& \operatorname{ETP}_{x}=-415,85+32,24 \cdot T_{\text {med }}-0,43 \cdot \bar{T}_{\text {med }}{ }^{2} \text { quando } \bar{T}_{\text {med }}>26,5 \\
& I=\sum_{n=1}^{12}\left(0,2 \cdot \bar{T}_{\text {med }}\right)^{1,514} \\
& a=6,75 \cdot 10^{-7} \cdot I^{3}-7,71 \cdot 10^{-5} \cdot I^{2}+1,7912 \cdot 10^{-2} \cdot I+0,49239 \\
& N=\frac{2}{15} \cdot \operatorname{arcos}[-1 \cdot(\operatorname{tg} \varphi \cdot \operatorname{tg} \delta)] \\
& C_{i}=\frac{N}{12} \cdot \frac{N D P_{i}}{30} \\
& E T P=E T P_{x} \cdot C_{i}
\end{aligned}
$$

em que: $E T P_{x}$ é a evapotranspiração potencial não corrigida para o $i$-ésimo mês considerado ( $i=1$ à 12$)$ ( $\left.\mathrm{mm}^{\text {mês }}{ }^{-1}\right)$; ETP é a evapotranspiração potencial corrigida para o i-ésimo mês considerado $\left(\mathrm{mm}\right.$ mês $\left.{ }^{-1}\right) ; \overline{\mathrm{T}}_{\text {med }}$ é a média climatológica da temperatura média do ar do i-ésimo mês ; I é o índice anual de calor; a é um índice térmico regional; $\mathrm{C}_{\mathrm{i}}$ é o fator de correção; $N D P_{i}$ é o número de dias do i-ésimo mês; Ni é o fotoperíodo do 150 dia do i-ésimo mês, considerado representativo da média mensal; $\varphi$ é a latitude e $\delta_{i}$ é a declinação solar do $15^{\circ}$ dia do $i$-ésimo mês, os quais foram obtidos para Itajubá.

\subsection{BALANÇO HÍDRICO CLIMATOLÓGICO}

Para o cômputo do balanço hídrico climatológico (BHC) foi utilizado o método proposto por Thornthwaite e Mather $(1955,1957)$ e simplificado por Pereira (2005), o qual fornece a quantidade de água armazenada no solo, evapotranspiração real (ETR), deficiência (DEF) e excedente hídrico (EXC) em nível local (SENTELHAS et al., 2008; SANTOS et al., 2017). Este método requer como dado de entrada as médias climatológicas mensais de precipitação acumulada $\left(\overline{\mathrm{P}}_{\text {med }}\right)$ e evapotranspiração potencial mensal $(\overline{E T P})$ obtida pelo método de Thornthwaite (1948), além do valor da capacidade de água disponível (CAD, mm). Por brevidade, adotou-se a $C A D=100 \mathrm{~mm}$, por ser o valor recomendado em estudos climatológicos que avaliam a DEF e o EXC em nível regional (SENTELHAS et al., 2008; MARTINS et al., 2018). Adicionalmente, - município de Itajubá possui cobertura pedológica com grande variação espacial (LIMA, 2012; FLAUZINO et al., 2016) com predominância de solos do grupo argissolos, latossolos, gleissolos e cambissolos em diferentes classes texturais (FLAUZINO et al., 2016). Todos esses solos possuem valores distintos de CAD e variam de acordo com a profundidade do perfil do solo considerando o mesmo grupo de solo (SENTELHAS et al., 2008; JERSZURKI et al., 2018), sendo coerente escolher um valor de CAD representativo.

Primeiramente faz-se necessário definir o mês (i) de inicialização do balanço hídrico. Neste sentido, duas situações podem ocorrer: Situação I - 
valores anuais de $\sum\left(\overline{\mathrm{P}}_{\text {med }}-\overline{E T P}\right) \geq 0$ ou $\sum\left(\overline{\mathrm{P}}_{\text {med }}-\overline{E T P}\right)^{+} \geq \mathrm{CAD}$, e Situação II: valores anuais de $\sum\left(\overline{\mathrm{P}}_{\text {med }}-\overline{E T P}\right)<0$ ou $\sum\left(\overline{\mathrm{P}}_{\text {med }}-\overline{E T P}\right)^{+}<\mathrm{CAD}$. Dependendo da situação foi adotado o critério de inicialização proposto em Pereira (2005). A partir de i, calcula-se simultaneamente o negativo acumulado (NEGACUM) e o armazenamento (ARM), através das expressões (PEREIRA, 2005):

Para a situação I:

$\operatorname{NEGACUM}_{i}=\bar{P}_{\text {med }_{i}}-\overline{E T P}_{i}$

$A R M_{i}=C A D \cdot e^{\left(\frac{N E G A C U M i}{C A D}\right)}$

Se $\overline{\mathrm{P}}_{\text {med }}-\overline{E T P}$ do mês $i+1<0$, calcula-se o $\operatorname{NEGACUM}_{i+1}$ (Equação 12 ) e para o cálculo do $\mathrm{ARM}_{i+1}$ utiliza-se a equação 11 .

$\operatorname{NEGACUM}_{i}=\operatorname{NEGACUM}_{i-1}+\left(\bar{P}_{\text {med }_{i}}-\overline{E T P}_{i}\right)$

Para os meses subsequentes $(\mathrm{i}+2, \mathrm{i}+3, \ldots, \mathrm{i}+\mathrm{n})$ em que $\bar{P}_{\text {med } \mathrm{i}+\mathrm{n}}-\overline{\operatorname{ETP}}_{\mathrm{i}+\mathrm{n}}$ $<0$, o mesmo procedimento é realizado (igual ao seguido para $\mathrm{i}+1$ ). Em caso de alterar os valores mensais de $\overline{\mathrm{P}}_{\text {med }}-\overline{E T P}(\geq 0)$, deve-se calcular primeiramente 0 ARM (equação 13) e posteriormente o NEGACUM (equação 14):

$A R M_{i}=A R M_{i-1}+\left(\bar{P}_{\text {med }_{i}}-\overline{E T P}_{i}\right)$

$N E G A C U M_{i}=C A D \cdot \ln \left(\frac{A R M i}{C A D}\right)$

Quando ARM for superior ao valor da CAD, assume-se que ARM = CAD e que o restante se refere aos valores de EXC.

Para a situação II:

Altera-se exclusivamente a equação utilizada para o mês de inicialização do balanço hídrico, da 10 para a equação 15 (PEREIRA, 2005):

$$
N E G A C U M_{i}=C A D \cdot\left[\ln \left(\frac{M}{C A D}\right)-\ln \left(1-e^{\frac{N}{C A D}}\right)\right]
$$

em que: $M$ é o acumulado de $\overline{\mathrm{P}}_{\text {med }}-\overline{E T P}$ da estação chuvosa (valores positivos de $\overline{\mathrm{P}}_{\text {med }}-\overline{E T P}>0$ ) e $\mathrm{N}$ é o acumulado de $\overline{\mathrm{P}}_{\text {med }}-\overline{E T P}$ da estação seca (valores negativos de $\overline{\mathrm{P}}_{\text {med }}-\overline{E T P}<0$ ).

Posteriormente, foram obtidos os valores de ETR (equações 16 e 17), DEF (equações 18 e 19) e EXC (equação 20), através de:

$E T R_{i}=\overline{E T P}$, quando $\left(\bar{P}_{\text {med }}-\overline{E T P}\right) i \geq 0$;

$$
\operatorname{ETR}_{i}=\bar{P}_{\text {med }_{i}}+\left|A R M_{i}-A R M_{i-1}\right| \text {, quando }\left(\bar{P}_{\text {med }}-\overline{E T P}\right)_{i}<0 .
$$

No cálculo do EXC, o qual se refere à quantidade de água excedente do período chuvoso e se perde do volume de controle por percolação (drenagem profunda) e/ou escorrimento superficial, considerou-se duas situações:

$E X C_{i}=0$, quando $A R M_{i}<C A D$;

$E X C_{i}=\left(\bar{P}_{\text {med }}-\overline{E T P}\right)_{i}-\left(A R M_{i}-A R M_{i-1}\right)$, quando $A R M=C A D$

A determinação da DEF foi calculada apenas quando $\left(\bar{P}_{\text {med }}-\overline{E T P}\right)_{i}<0$, caso contrário a DEF é nula:

$D E F_{i}=\overline{E T P}_{i}-E T R_{i}$, quando $\left(\bar{P}_{\text {med }}-\overline{E T P}\right)_{i}<0$.

Após as etapas de cálculo foi realizada as aferições do balanço hídrico, conforme recomendações de Pereira (2005). 


\subsection{ANÁLISE DO IMPACTO DAS MUDANÇAS CLIMÁTICAS}

Para verificar o impacto das mudanças climáticas no balanço hídrico climatológico (BHC) para Itajubá, calculou-se a ETP e o BHC com os valores médios das variáveis climáticas $\left(\bar{T}_{\text {med }}\right.$ e $\left.\bar{P}_{\text {med }}\right)$ simuladas para o PP (1979-2005) e projetadas para o FP (2021-2049) e FD (2071-2099). Por fim, analisaram-se as projeções de mudança das variáveis do extrato do balanço hídrico climatológico anual (ETP, DEF, EXC), considerando o RCP8.5, através do comparativo com o $\mathrm{PP}$, e o provável impacto das mudanças projetadas nas principais culturas agrícolas de Itajubá: milho, batata, feijão e café. Optou-se por essas culturas pelo fato da sua maior representação na economia do município (SIDRA, 2019).

\section{RESULTADOS E DISCUSSÃO}

\subsection{CLIMA PRESENTE}

Os dados do CPC têm sido validados e utilizados em trabalhos no Brasil e no estado de Minas Gerais como demonstrado em Silva e Reboita (2013). Principalmente pelo fato de algumas localidades, como é o caso de Itajubá, possuírem estações meteorológicas automáticas instaladas somente a partir de 1998, e por isso, não possuem séries temporais suficientes para estudos climáticos aplicados a mudanças climáticas.

Dessa forma, preliminar a este estudo foi realizada a validação através da comparação entre os dados de temperatura média do ar provenientes da estação meteorológica automática no 32512 (pertencente ao Sistema de Meteorologia e Recursos Hídricos de Minas Gerais - SIMGE e conveniada pelo Instituto Nacional de Pesquisas Espaciais - INPE) e os dados da análise do CPC para o período de 2000 a 2017 (Figura 1). Como as estatísticas calculadas apresentaram similaridades entre os dois conjuntos de dados (Tabela 1), o dado do CPC foi considerado adequado para este estudo climático.
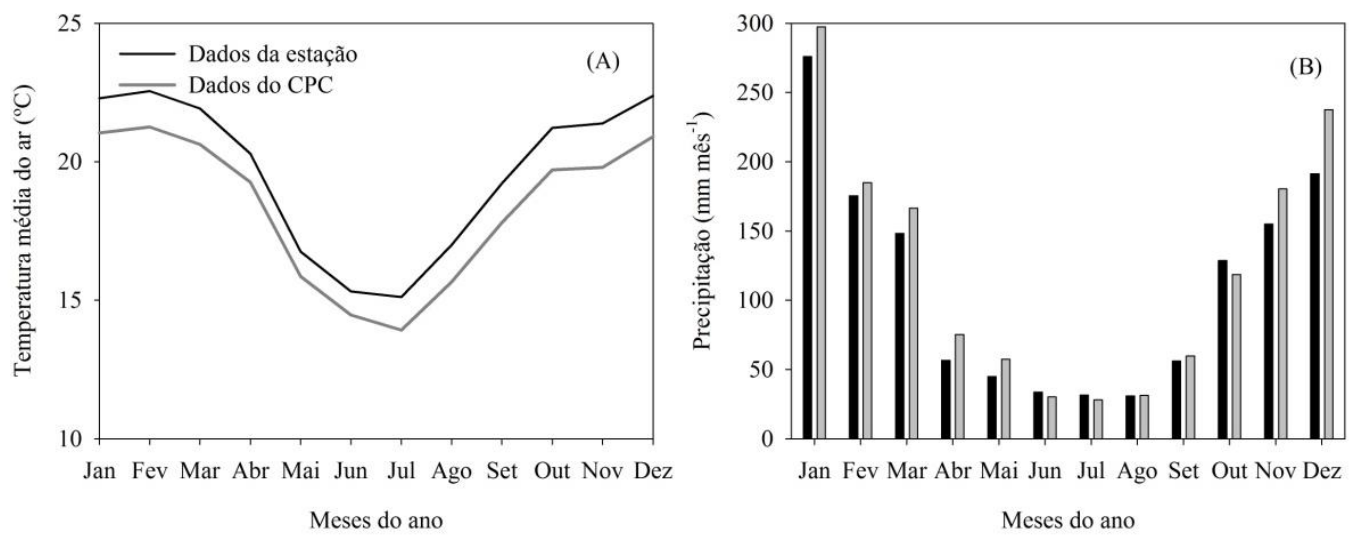

Figura 1 - Ciclo anual de temperatura média do ar (A) e precipitação acumulada mensal (B) provenientes dos dados da estação meteorológica automática localizada no campus da Universidade Federal de Itajubá e do Climate Prediction Center (CPC) ambos para o período de 2000-2017 para Itajubá (MG). Em cinza, dados do CPC, em preto, dados da estação. 
Tabela 1 - Avaliação da comparação dos dados de temperatura média do ar e precipitação acumulada mensal entre os dados do Climate Prediction Center (CPC) e a estação meteorológica automática, Itajubá (MG) (2000-2017).

\begin{tabular}{|c|c|c|c|c|}
\hline \multirow{2}{*}{ Meses do ano } & \multicolumn{2}{|c|}{$\begin{array}{c}\text { Temperatura média } \\
\text { do ar }\left({ }^{\circ} \mathrm{C}\right)\end{array}$} & \multicolumn{2}{|c|}{$\begin{array}{l}\text { Precipitação acumulada } \\
\left.\text { ( } \mathrm{mm} \text { mês }{ }^{-1}\right)\end{array}$} \\
\hline & RQME* & $\begin{array}{l}\text { Viés Médio } \\
(\mathrm{VM}) * *\end{array}$ & RQME* & $\begin{array}{l}\text { Viés Médio } \\
(\mathrm{VM}) * *\end{array}$ \\
\hline Janeiro & 1,34 & $-1,25$ & 88,06 & 21,47 \\
\hline Fevereiro & 1,36 & $-1,29$ & 40,97 & 9,40 \\
\hline Março & 1,33 & $-1,29$ & 41,50 & 18,21 \\
\hline Abril & 1,09 & $-1,03$ & 35,02 & 18,66 \\
\hline Maio & 0,97 & $-0,90$ & 25,37 & 12,43 \\
\hline Junho & 1,02 & $-0,85$ & 15,81 & $-3,55$ \\
\hline Julho & 1,98 & $-1,19$ & 49,56 & $-3,39$ \\
\hline Agosto & 1,43 & $-1,33$ & 15,17 & 0,49 \\
\hline Setembro & 1,48 & $-1,42$ & 19,57 & 3,69 \\
\hline Outubro & 1,59 & $-1,52$ & 104,19 & $-10,08$ \\
\hline Novembro & 1,67 & $-1,59$ & 60,31 & 25,41 \\
\hline Dezembro & 1,54 & $-1,47$ & 66,31 & 46,17 \\
\hline \multicolumn{5}{|c|}{$\begin{array}{l}\text { *RQME = raiz do quadrado médio do erro, dado por: RQME }=\left[\sum_{i=1}^{n}(E i-O i)^{2} / N\right]^{0,} \\
* * \mathrm{VM}=\text { Viés médio, dado por: VM }=N^{-1} \sum_{i=1}^{n}\left(E_{i}-O_{i}\right) \text { (MARTINS et al., 2014) } \\
\text { Em que Ei }=\text { valores de Tmed e Pmed simulado provenientes do Climate } \\
\text { Prediction Center (2000-2017); Oi }=\text { valores de Tmed e Pmed referente aos } \\
\text { dados observados pela estação } 32512(2000-2017), N=\text { número de } \\
\text { observações. }\end{array}$} \\
\hline \multirow{2}{*}{\multicolumn{5}{|c|}{$\begin{array}{l}\text { A comparação entre os dados simulados pelo RegCM4 e os dados d } \\
\text { análise do CPC, ambos para o PP }(1979-2005) \text {, mostram um viés pequen } \\
\left(<1,6^{\circ} \mathrm{C}\right) \text { do modelo e boa representação do ciclo anual da } \bar{T}_{\text {med }} \text {. Já para } \\
\left.\text { precipitação há um maior viés }\left(\bar{P}_{\text {med }}<103 \mathrm{~mm} \text { mês }{ }^{-1}\right) \text { (Tabela } 2 \text { e Figura } 2\right) \text {. } \\
\text { Tabela } 2 \text { - Avaliação da simulação dos dados de temperatura média do ar e precipitaçãa } \\
\text { acumulada mensal entre o modelo regional RegCM4 e os dados do Climate Predictio } \\
\text { Center (CPC) (1979-2005). }\end{array}$}} \\
\hline & & & & \\
\hline \multirow{2}{*}{ Meses do ano } & \multicolumn{2}{|c|}{$\begin{array}{c}\text { Temperatura média } \\
\text { do ar }\left({ }^{\circ} \mathrm{C}\right)\end{array}$} & \multicolumn{2}{|c|}{$\begin{array}{l}\text { Precipitação acumulada } \\
\left(\mathrm{mm} \mathrm{mês}^{-1}\right)\end{array}$} \\
\hline & RQME* & $\begin{array}{l}\text { Viés Médio } \\
(\mathrm{VM}) * *\end{array}$ & RQME* & $\begin{array}{l}\text { Viés Médio } \\
(\mathrm{VM})^{* *}\end{array}$ \\
\hline Janeiro & 1,8 & $\sim 0$ & 158,3 & $-103,7$ \\
\hline Fevereiro & 1,6 & $-0,3$ & 123,4 & $-50,4$ \\
\hline Março & 2,3 & $-1,6$ & 91,5 & $-37,3$ \\
\hline Abril & 1,8 & $-0,5$ & 45,9 & $-12,9$ \\
\hline Maio & 1,9 & 0,2 & 51,2 & $-21,5$ \\
\hline Junho & 1,3 & $-0,1$ & 69,8 & 34,6 \\
\hline Julho & 1,9 & $-0,5$ & 61,9 & 37,3 \\
\hline Agosto & 2,3 & $-1,1$ & 92,4 & 55,5 \\
\hline Setembro & 2,6 & $-1,5$ & 98,1 & 36,8 \\
\hline Outubro & 1,9 & $-0,7$ & 78,1 & 17,3 \\
\hline
\end{tabular}




$\begin{array}{llllc}\text { Novembro } & 2,3 & -0,2 & 108,6 & 9,0 \\ \text { Dezembro } & 2,2 & -1,2 & 137,4 & -42,8\end{array}$

*RQME $=$ raiz do quadrado médio do erro, dado por: $\mathrm{RQME}=\left[\sum_{i=1}^{n}(E i-O i)^{2} / N\right]^{0,5}$

** $\mathrm{VM}=$ Viés médio, dado por: $\mathrm{VM}=N^{-1} \sum_{i=1}^{n}\left(E_{i}-O_{i}\right)$ (MARTINS et al., 2014). $\mathrm{Em}$ que $\mathrm{Ei}=$ valores de Tmed e Pmed simulado pelo modelo RegCM4 para o PP (1979-2005); Oi = valores de Tmed e Pmed referente aos dados observados do CPC para o PP (1979-2005), N = número de observações.
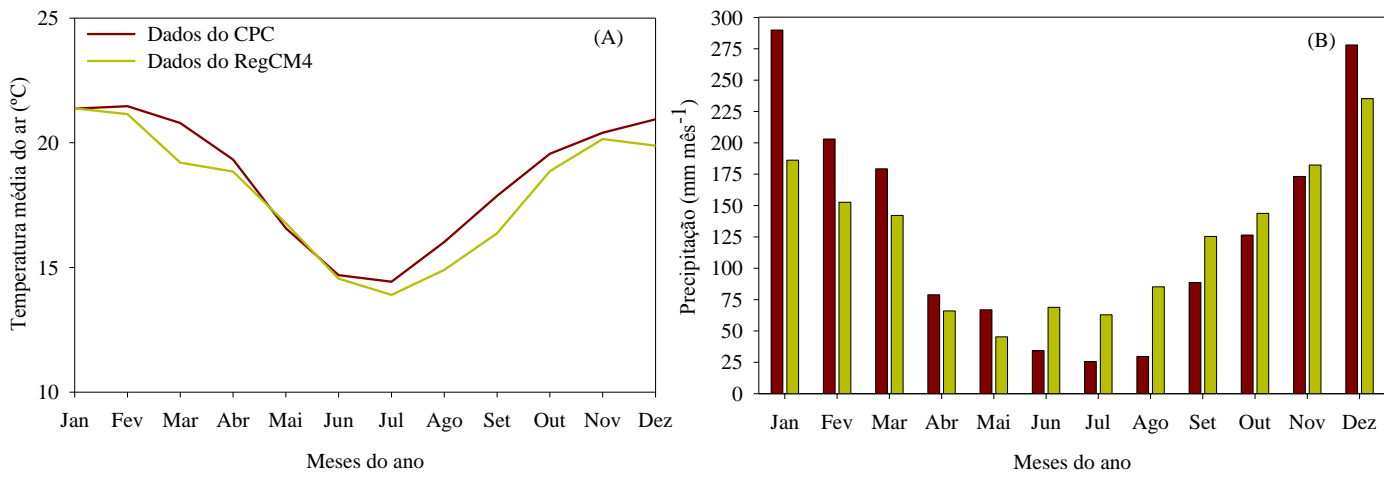

Figura 2 - Ciclo anual de temperatura média do ar (A) e precipitação acumulada mensal (B) provenientes dos dados do Climate Prediction Center (CPC) e simulados pelo modelo regional de previsão climática RegCM4 para o período de 1979-2005 para Itajubá (MG).

Apesar de existir maior proximidade e melhor representatividade do ciclo anual para a $\bar{T}_{\text {med }}$ e maior variabilidade para a $\bar{P}_{\text {med }}$, principalmente para o mês de janeiro, o RegCM4 consegue reproduzir o comportamento mensal de ambas variáveis, semelhante ao observado por Reboita et al. (2018b). No caso da $\bar{T}_{\text {med }}$, as simulações do modelo foram ligeiramente mais frias que o dado do CPC, principalmente nos meses de março $\left(\mathrm{VM}=-1,6^{\circ} \mathrm{C}\right.$ ) e setembro ( $\mathrm{VM}=-1,5^{\circ} \mathrm{C}$ ) (Figura 2A). Já no caso da $\bar{P}_{\text {med }}$, apesar do RegCM4 ser hábil em representar 0 ciclo anual, apresenta diferenças nos valores mensais: subestimativa do modelo nos meses de verão ( $D J F$, com VM $=-65,6 \mathrm{~mm}$ mês $^{-1}$ ) e outono (MAM, com VM $=-35,8 \mathrm{~mm}$ mês $^{-1}$ ) e superestimativa nos meses de inverno (JJA, com VM = $+42,5 \mathrm{~mm} \mathrm{mês}^{-1}$ ) e primavera ( $\mathrm{SON}, \mathrm{VM}=+21,0 \mathrm{~mm}$ mês ${ }^{-1}$ ) (Figura 2B). Apesar das simulações do RegCM4 serem mais secas (úmidas) no verão (inverno), há uma compensação anual o que justifica a utilização dos dados simulados do RegCM4 para representar o clima presente (1979-2005) (REBOITA et al., 2018b) e serem utilizadas no cômputo da ETP e do balanço hídrico climatológico para Itajubá.

\subsection{CLIMA FUTURO}

\subsubsection{TEMPERATURA, PRECIPITAÇÃO, EVAPOTRANSPIRAÇÃO POTENCIAL E BALANÇO HÍDRICO CLIMATOLÓGICO}

Com relação ao clima futuro, as projeções do RegCM4 indicam um aumento crescente e gradual de temperatura média do ar em Itajubá (Figura $3 \mathrm{~A})$, principalmente no mês de setembro $\left(\sim 6^{\circ} \mathrm{C}\right)$. Os aumentos poderão alcançar $\sim 1,8^{\circ} \mathrm{C}$ no outono (MAM) no FP (2021-2049) e $\sim 5^{\circ} \mathrm{C}$ no FD (20712099) no inverno (JJA) e primavera (SON) (Figura 3B). Além disso, projeta-se 
uma tendência heterogênea da precipitação acumulada, sendo que na primavera e no verão (SON, DJF) existe projeção de aumento e no outono e no inverno (MAM, JJA) projeção de diminuição da precipitação acumulada mensal (Figura 3D), resultados que corroboram com Tavares et al. (2018), Reboita et al. (2018b), Santos et al. (2017) e Florêncio et al. (2019). Cabe ressaltar que os autores citados utilizam diferentes modelos para as projeções climáticas e, especialmente, Santos et al., (2017) e Florêncio et al., (2019), utilizam dados de projeções climáticas oriundos de modelos globais e, mesmo assim, estão coerentes com o presente estudo.
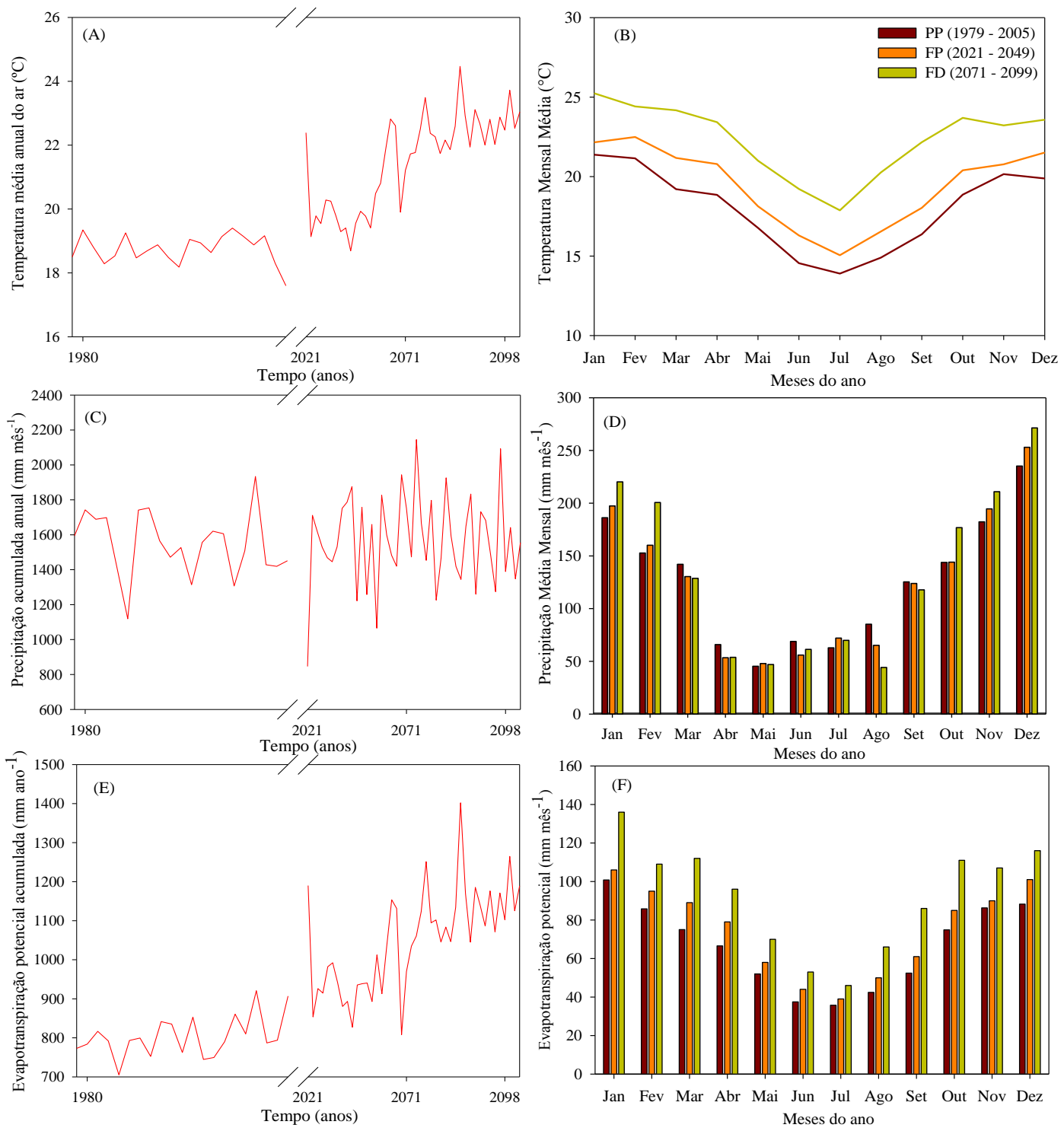

Figura 3 - Variação temporal simulada (1979-2005) e projetada (2021 - 2099) e padrão mensal da temperatura média do ar $(A, B)$, precipitação acumulada anual/mensal $(C, D)$, evapotranspiração acumulada anual/mensal $(E, F)$ para Itajubá considerando o período atual (1979-2005), futuro próximo (2021-2049) e futuro distante (2071-2099) obtidas pelo modelo regional RegCM4 e cenário forçante RCP8.5. Devido aos valores, os eixos das variáveis estão em escalas diferentes. 
Esse padrão heterogêneo de projeção da $\bar{P}_{\text {med }}$ associado ao aumento da $\bar{T}_{\text {med }}$ (Figura 3A-D) reflete diretamente em mudança mensal (sazonal) e anual da ETP (Figura 3E,F) e alteram a demanda atmosférica (LEMOS FILHO et al., 2010), impactando no BHC (SANTOS et al., 2017). De maneira geral, a projeção da ETP seguirá o mesmo padrão da $\bar{T}_{\text {med }}$ e $\bar{P}_{\text {med }}$ (Figura $3 \mathrm{~A}, \mathrm{C}$ ), sendo intensificada no FD (2071-2099) (Figura 3E). De maneira específica, projeta-se aumento da ETP em todos os meses do ano, porém os meses de março, outubro e janeiro terão os maiores aumentos, com valores superiores a $35 \mathrm{~mm}$ mês ${ }^{-1}$. Em uma análise mais detalhada percebe-se que, justamente nos meses da primavera (SON), em que há os maiores aumentos projetados de $\bar{T}_{\text {med }}\left(\sim 5^{\circ} \mathrm{C}\right)$, e verão (DJF) (Figura 3B) haverá os maiores aumentos de ETP (Figura 3F). Isso indica que apesar do aumento de extremos (chuvas acima da média) justamente em SON e DJF (Figura 3D), a demanda evaporativa será maior pelo impacto do aumento da temperatura do ar. Isso reflete diretamente em alterações no extrato do BHC (ETR, DEF e EXC) (Figura 4). 

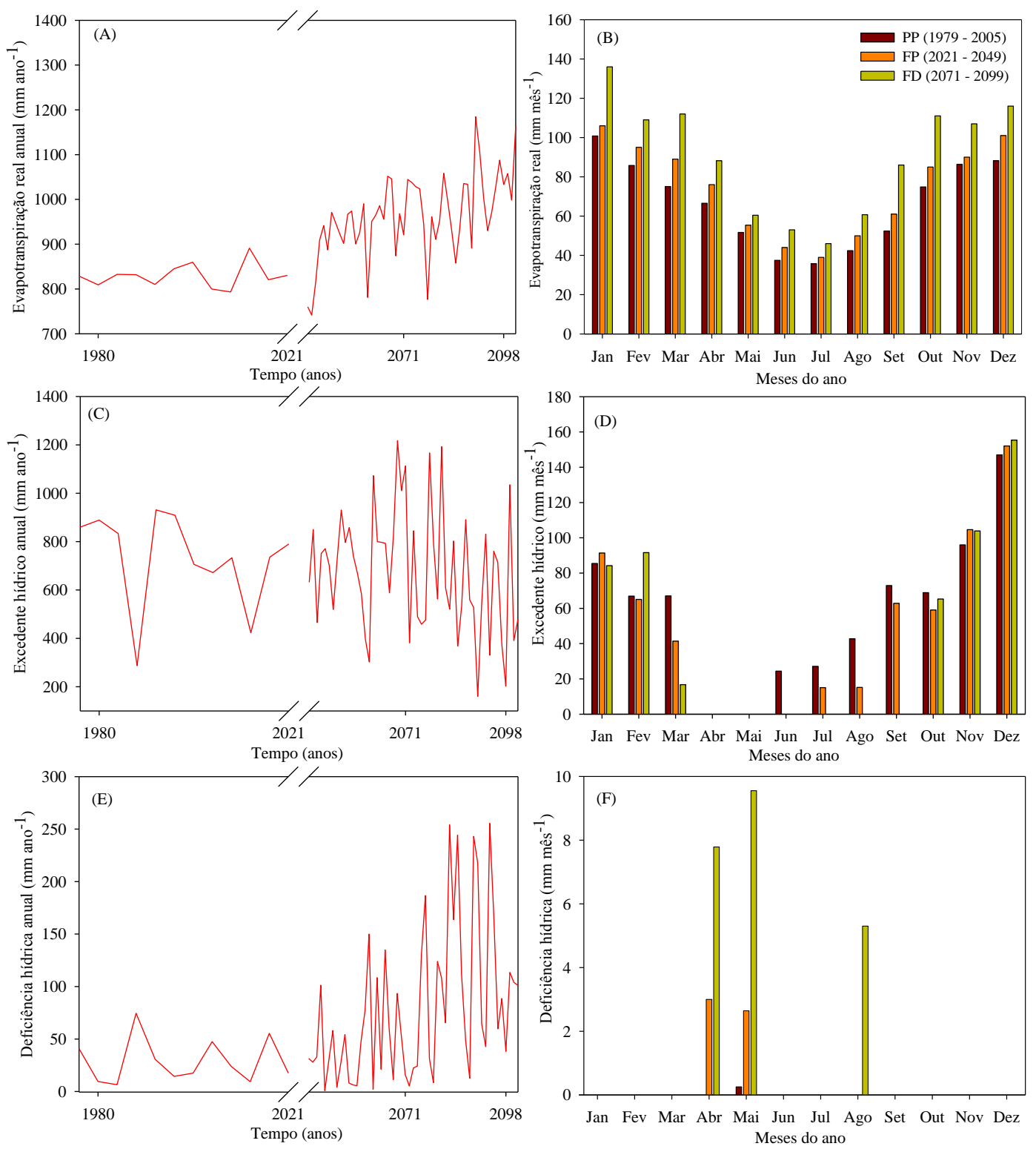

Figura 4 - Variação temporal simulada (1979-2005) e projetada (2021 - 2099) para a evapotranspiração real anual $(A)$, excedente hídrico anual $(C)$ e deficiência hídrica anual (E) para o cenário forçante RCP8.5; e padrão mensal da evapotranspiração real acumulada (B), excedente hídrico (D) e deficiência hídrica (F) para Itajubá (MG), considerando o período atual (1979-2005), futuro próximo (2021-2049) e futuro distante (2071-2099) para o cenário forçante RCP8.5. Devido aos valores, os eixos das variáveis estão em escalas diferentes.

Com relação ao balanço hídrico, percebe-se aumentos nos valores de ETR, seguindo exatamente o padrão esperado, devido à combinação entre o aumento da ETP e $\bar{P}_{\text {med }}$, principalmente nos meses da primavera (SON) e verão (DJF) (Figura 4A,B), chegando a $37 \mathrm{~mm}^{\text {mês }}{ }^{-1}$ em março no FD (Figura 4B), corroborando com os resultados de Cardoso e Justino (2014). 
Já com relação ao excedente hídrico (EXC), haverá padrão heterogêneo de alteração desta variável, convergindo para ligeira redução no final do século XXI (Figura 4C). No entanto, o padrão sazonal de alteração é distinto, com aumento no verão (DJF) e redução no outono (MAM) e primavera (SON) (Figura 4D). No inverno (JJA), o padrão climatológico do EXC no PP, de chuvas abaixo da média ( $60 \mathrm{~mm}$ ), será intensificado, ou seja, haverá redução da $\bar{P}_{\text {med }} \mathrm{e}$ consequentemente do EXC nesses meses. Já nos meses SON e DJF é projetado o oposto, com aumento da $\bar{P}_{\text {med }}$ e EXC. Esse padrão também foi observado por Santos et al. (2017) e Reboita et al. (2018a) para a região sul de Minas Gerais, e ocorre devido ao aumento projetado da $\bar{P}_{\text {med }}$ acima da média ( $190 \mathrm{~mm}$ ) para o verão (Figura 3C,D), elevando os valores de excedente hídrico em Itajubá.

O aumento do EXC no verão pode não ser benéfico. Primeiro, pois indica aumento de episódios de eventos extremos, conforme relatado em Reboita et al., (2018a), o que ocasiona maiores volumes de chuva em curto espaço de tempo e, segundo, pois acarreta o aumento da água em excesso que pode configurar como água nociva. Ambas as situações, combinadas com o relevo de Itajubá, constituem em aumento da vazão líquida e sobrecarga do sistema de drenagem, o qual se encontra atualmente subdimensionado não comportando o escoamento. Isso causará enchentes e inundações em cotas superiores a eventos anteriores, além de perdas econômicas para a população residente, principalmente, em zonas de várzea.

Nos meses de abril, maio e junho (Figura 4D), as projeções de EXC no FP e FD são de $\sim 0 \mathrm{~mm}$, indicando redução do volume de água no solo e início de situação de déficit hídrico (DEF) (Figura 4E,F). Nesse aspecto, projeta-se aumento da DEF justamente nesses meses, além de agosto. Porém, as projeções da DEF ao longo do século, indicam ligeiro aumento da DEF acumulada no final do século XXI, principalmente entre 2080-2090, de aproximadamente $100 \mathrm{~mm}$ (Figura 4E), semelhante ao observado por Santos et al. (2017) na região sul e sudeste de MG.

Mesmo com a tendência de pequeno aumento da DEF e redução do EXC, ambas as situações poderão causar prejuízos no setor agrícola, pois agrava a aridez entre os meses de abril a setembro (principalmente em JJA), que coincidem com o plantio de culturas de verão e com o enchimento de grãos ou formação do fruto nos plantios precoces de culturas de inverno, principalmente realizados entre março-abril. Como exemplo vale citar a influência dessas situações nas três culturas anuais que apresentam maior representatividade em termos de área plantada em Itajubá no ano de 2018/2019 (SIDRA, 2019): milho (1 ${ }^{a}$, com área plantada de $60 \mathrm{ha}$ ) batata (2a, com área plantada de 19 ha) e feijão ( $3^{a}$, com área plantada de 15 ha).

\subsubsection{IMPACTOS DAS MUDANÇAS CLIMÁTICAS NAS PRINCIPAIS CULTURAS EM ITAJUBÁ}

Para uma análise mais aprofundada dos impactos das mudanças climáticas em culturas agrícolas é necessário aplicar os dados de projeções climáticas em modelos de desenvolvimento e produtividade, os quais devem ser primeiramente calibrados experimentalmente para as condições climáticas do local (FAGUNDES et al., 2010b; HEINEMANN et al., 2017; FLORENCIO et al., 2019; MARTINS et al., 2019). Por isso, analisamos apenas o impacto projetado da DEF e EXC nas principais culturas agrícolas cultivadas em Itajubá. 
O milho é susceptível à DEF especialmente durante o pendoamento, florescimento, polinização (RAMIREZ-CABRAL et al., 2017) e, principalmente, durante o enchimento de grãos, no qual a DEF causa perdas de $90 \%$ no rendimento (DOORENBOS; KASSAM, 1979; RAMIREZ-CABRAL et al., 2017; RESENDE et al., 2019). Em Itajubá, o enchimento de grãos ocorre entre os meses de janeiro, nos plantios antecipados no decêndio 28: 05/10, a abril, nos plantios tardios no decêndio 36: 25/12 (MAPA, portaria n055), justamente no período que ocorre aumento da DEF (Figura 3F). Por outro lado, prejuízos também decorrem do aumento do EXC na fase que antecede o pendoamento (RESENDE et al., 2019), que ocorre entre os meses de novembro, nos plantios antecipados no decêndio 28: 05/10, a fevereiro, nos plantios tardios no decêndio 36: 25/12 (MAPA, portaria n055). Justamente aqueles em que há projeção de aumento da $\bar{P}_{\text {med }}$ (Figura 2D) e do EXC (Figura 3D). O excesso de água no solo causa danos às raízes de milho, devido ao acúmulo de bioprodutos tóxicos (RAMIREZ-CABRAL et al., 2017), reduz a fotossíntese, devido ao aumento de dias nublados (RESENDE et al., 2019), reduzindo o acúmulo de biomassa e o rendimento. Ou seja, o milho será duplamente prejudicado nos cenários de mudanças climáticas projetados em Itajubá.

A batata é uma cultura suscetível, majoritariamente, em condições de temperaturas elevadas e, minoritariamente, aos padrões irregulares de precipitação, exatamente o padrão projetado para Itajubá (Figura $2 A, B, C, D$ ). Em Itajubá cultiva-se preferencialmente entre os meses de agosto a outubro, colhendo a partir de meados de novembro até 0 final de janeiro, respectivamente. Aumentos projetados de $\bar{T}_{\text {med }}$ poderão causar prejuízos ao cultivo da batata em Itajubá. Isso ocorre devido ao mecanismo de bioconversão das plantas C3, o qual a batata está inserida, sendo que em condições de temperatura elevada ocorre o efeito de Warbung, onde $\mathrm{o}_{2} \mathrm{O}_{2}$ inibe a fixação da $\mathrm{CO}_{2}$ pela rubisco ${ }^{1}$, reduzindo a fotossíntese e elevando a fotorrespiração (MARENCO; LOPES, 2009). Essa combinação reduz a qualidade dos tubérculos (aumento de rachaduras e necroses) e a produtividade (FAGUNDES et al., 2010 a,b). Em cultivos de batata no sul de MG, o aumento da temperatura média do ar causa atrasos no início da tuberização e no início do florescimento, redução na partição de fotoassimilados para os tubérculos e redução de $25,5 \%$ na produtividade (MENEZES et al., 1999). Além disso, aumento de $\bar{T}_{\text {med }}$ na fase de início da tuberização, que ocorre entre os meses setembro nos plantios antecipados em agosto, a novembro nos plantios tardios em outubro, favorecem o crescimento da parte aérea em detrimento dos tubérculos. Isso afeta a quantidade e a qualidade da produção, devido ao atraso da tuberização e à manifestação de defeitos fisiológicos e deformações nos tubérculos, como embonecamento, coração oco, rachaduras e necroses (BISOGNIN; STRECK, 2009; FAGUNDES et al., 2010 a,b). Em geral, cada aumento projetado de $1^{\circ} \mathrm{C}$ reduz $1 \%$ na produtividade da batata (FAGUNDES et al., 2010 a,b).

Concomitante, exigem-se temperaturas amenas e EXC moderado na fase de maturação dos tubérculos, que ocorre de novembro (plantios em agosto) a janeiro (plantios em outubro). Padrões diferentes deste, como o projetado em Itajubá, aceleram o processo de maturação das plantas de batata. Quanto mais curto for o estágio de maturação das plantas menores são as quantidades de

\footnotetext{
1 RUBISCO = enzima ribulose $1-5$ bifosfato carboxilase-oxigenase responsável pelo processo metabólico que governa a fotossíntese (FLORÊNCIO et al., 2019).
} 
assimilados transloucados para os tubérculos e, em consequência, menor é o teor final de matéria seca. (Figuras 2B, 3D) (BISOGNIN; STRECK, 2009; ZANON et al., 2013).

A cultura do feijão, resumidamente, é sensível tanto à presença quanto ausência de precipitação, uma vez que ambas afetam a disponibilidade hídrica do solo, o que influencia a absorção de água e nutrientes pelas raízes (HEINEMANN et al., 2009). Em períodos de estiagem, as principais respostas são a redução da área foliar, modificações no sistema radicular, redução da condutância e fechamento estomático, fatores determinantes na redução da assimilação do carbono e, consequentemente, levam à diminuição da fotossíntese e produtividade, além do atraso na maturação do feijão (DARKWA et al., 2016; MATHOBO et al., 2017).

As safras de feijão mais impactadas em Itajubá, provavelmente, serão a $2^{a}$ e $3^{a}$, com data média de plantio em 25/jan e 05/jul, respectivamente (SANTOS et al., 2018). A $2^{a}$ safra será impactada durante o florescimento, que vai do início de março a abril, enquanto a $3^{a}$ será impactada na germinação, florescimento (pré-floração e floração) e frutificação (formação e enchimento das vagens). A DEF durante o florescimento, que vai de julho a agosto, provoca o aborto e a queda das flores, reduzindo o número de vagens por planta e o rendimento médio (HEINEMMAN et al., 2016; HEINEMANN et al., 2017; SANTOS et al., 2018). A DEF durante a frutificação, que vai de agosto a setembro, induz a queda das vagens recém-formadas, prejudica a formação de sementes nas vagens, diminui a massa e o rendimento (OLIVEIRA et al., 2018). Além disso, o plantio da $3^{a}$ safra ocorre justamente nos meses de julho e agosto sendo necessárias chuvas para que ocorra a germinação uniforme das sementes (SANTOS et al., 2018). Entretanto, chuvas excessivas reduzem a oxigenação do solo e a atividade radicular, afetando a absorção de água e nutrientes pelo feijoeiro (HEINEMANN et al., 2009).

Adicionalmente, Itajubá produz o equivalente a $\mathrm{R} \$ 1.326 .000 \mathrm{em}$ produtos de culturas permanentes e temporárias, sendo o café a cultura mais significante para o município, representando $21,19 \%$ do valor total da produção (IBGE, 2017). Nesse sentido, o aumento projetado de temperatura ( $\geq 25^{\circ} \mathrm{C}$ em janeiro) (Figura 3B) é o que mais impactará o café (TAVARES et al., 2018), pois exige-se temperaturas médias entre 18 e 22,5 ${ }^{\circ} \mathrm{C}$ e DEF $<150 \mathrm{~mm}$. Tal aumento prejudicará a frutificação, resultando em baixa produtividade (SEDIYAMA et al., 2001). O café possui um ciclo fenológico de dois anos, sendo, portanto, mais susceptível aos efeitos das variações climáticas em qualquer uma de suas seis fases de desenvolvimento (CAMARGO, 2001). Na florada, que ocorre entre a primavera e verão do segundo ano, há um aumento do potencial hídrico nas gemas florais maduras. Quando há excesso de água recebida nessa fase, como projetado para os meses primavera e verão (Figura 2D), ocorre o fenômeno de floração indefinida, o que atrasa a fase de granação dos frutos. Além disso, temperaturas elevadas, durante o início da florada, como projetado para o final do século XXI (Figura 2B), provoca a morte do tubo polínico pela desidratação, causando o abortamento das flores (CAMARGO, 2001). Essas mudanças podem reduzir a qualidade do café e as áreas de aptidão ao cultivo do mesmo na região sul de Minas Gerais ( $25 \%$ ), conforme observado por Tavares et al. (2018), além do deslocamento do cultivo somente para locais de maior altitude. Esse cenário dificultará o plantio e a realização dos tratos culturais devido à movimentação do maquinário e à falta de adaptabilidade dos 
produtores que em sua maioria se classificam como agricultura familiar (TAVARES et al., 2018).

Devido ao impacto significativo nas principais culturas anuais e perenes cultivadas em Itajubá, algumas estratégias deverão ser adotadas para minimizar os impactos. As principais estratégias para a redução dos impactos negativos são: a escolha e a seleção de espécies, cultivares e variedades mais tolerantes, atualização constante dos mapas de aptidão climática e zoneamento agrícola, alteração dos locais de cultivo, modificações das épocas mais recomendadas ao plantio e alteração das práticas de manejo.

Além do setor agrícola, o setor energético também sofrerá com os impactos projetados em Itajubá. Como se sabe, o município possui duas pequenas centrais hidrelétricas $(\mathrm{PCH}$ ) instaladas e em funcionamento ( $\mathrm{PCH}$ Luiz Dias e PCH São Bernardo), além de diversas centrais geradoras hidrelétricas (CGH), gerando um total de $8,4 \mathrm{MW}$, e com a diminuição da $\bar{P}_{\text {med }}$ projetada entre os meses março e setembro, a geração de energia hidrelétrica poderá sofrer com a diminuição do volume útil disponível, sendo necessária a compensação desse déficit de geração de energia através da utilização de combustíveis fosseis, favorecendo ainda mais a aceleração das mudanças climáticas. Além disso, essa diminuição no volume de $\bar{P}_{\text {med }}$ prejudicará a recarga de águas subterrâneas que recarregam os rios e mananciais em períodos de estiagem, causando problemas no abastecimento público e na falta de água para a irrigação que será cada vez mais necessária devido ao aumento do déficit hídrico no solo.

\section{CONCLUSÃO}

A combinação entre os padrões irregulares de precipitação, com aumento nos meses de primavera/verão e redução nos meses de outono/inverno, e aumento de $\sim 5{ }^{\circ} \mathrm{C}$ na temperatura, poderão impactar as principais culturas anuais e perenes cultivadas em Itajubá, alterando a fenologia do desenvolvimento e as áreas destinadas ao plantio. A deficiência hídrica será intensificada, principalmente nos meses mais secos do ano (JJA), enquanto o excedente hídrico será intensificado nos meses mais chuvosos (DJF). Para os usuários de recursos hídricos, haverá prejuízos ambientais e econômicos, pois com o aumento da vazão líquida, o sistema de drenagem poderá não comportar o escoamento, causando enchentes e inundações em cotas superiores a eventos anteriores, causando perdas econômicas para a população residente em zonas de várzea, além de possíveis deslizamentos devido à saturação do solo nas encostas. Na questão ambiental, o aumento da produção de água nociva pode destruir áreas de reprodução de peixes e anfíbios, acarretando em alterações no ecossistema, como a proliferação de vetores, além de aumentar a necessidade de investimento em projetos de recuperação ambiental, que podem ocasionar indiretamente no aumento das tarifas de outorga de recursos hídricos para os usuários.

Já para os produtores rurais, o aumento do excedente hídrico nos meses de DJF prejudicará o retorno financeiro acarretando quebra de produtividade, principalmente nas culturas de verão, como a batata, feijão, milho, assim como a oliveira, as quais são cultivadas na região de Itajubá. Isso ocorre pois o aumento do volume de chuva satura o solo, reduz a transpiração e 
consequentemente a entrada de $\mathrm{CO}_{2}$ para a realização da fotossíntese, diminuindo a produção de fotoassimilados. Por outro lado, causa prejuízos no crescimento radicular e na formação de tubérculos, acarretando em tubérculos de menor tamanho ou insuficientes para a comercialização.

\section{REFERÊNCIAS BIBLIOGRÁFICAS}

AMBRIZZI, T.; REBOITA, M. S.; DA ROCHA, R. P.; LLOPART, M. The state-ofthe-art and fundamental aspects of Regional Climate Modeling in South America. Annals of the New York Academy of Sciences, especial edition: Climate Science, p. 1-23, 2018.

ASSAD, E. D.; MARTINS, S. C.; BELTRÃO, N. E. M.; PINTO, H. S. Impacts of climate change on the agricultural zoning of climate risk for cotton cultivation in Brazil. Pesquisa Agropecuária Brasileira, v. 48, n. 1, p. 1-8, 2013.

ASSAD, E. D.; PINTO, H. S.; ZULLO JUNIOR, J.; ÁVILA, A. M. H. Impacto das mudanças climáticas no zoneamento agroclimático do café no Brasil. Pesquisa Agropecuária Brasileira, v. 39, n. 11, p. 1057-1064, 2004

BARBOSA, A. A.; OLIVEIRA, G. M.; OLIVEIRA, T. J. Histórico de enchentes em Itajubá/MG. Revista Meio Ambiente e Sustentabilidade, v. 9, n. 4, p. 125-140, 2015.

BISOGNIN, D. A.; STRECK, N. A. Desenvolvimento e manejo das plantas para alta produtividade e qualidade da batata. Itapetininga: Associação Brasileira da Batata. 2009, 30 p. Disponível em: <http://w3.ufsm.br/fitotecnia/images/Batata.pdf> Acesso em: 21 de junho de 2019.

CAMARGO, A. P.; CAMARGO, M. B. P. Definição e esquematização das fases fenológicas do cafeeiro arábica nas condições tropicais do Brasil. Bragantia, v. 60 , n. 1 , p. $65-68,2001$.

CARDOSO, G. M.; JUSTINO, F. Simulação dos componentes da evapotranspiração sob condições climáticas atuais e de cenários climáticos futuros de aquecimento global com o uso de modelos de clima-vegetação. Revista Brasileira de Meteorologia, v.29, p.85-95, 2014.

CHEN, M.; SHI, W.; XIE, P.; SILVA, V.B.S.; KOUSKY, V.E.; WAYNE HIGGINS, R.; JANOWIAK, J.E. Assessing objective techniques for gauge-based analyses of global daily precipitation. Journal of Geophysical Research, v. 113, n.4, p. 1-13, 2008.

CUADRA, S. V.; ROCHA, R. P. da. Simulação numérica do clima de verão sobre o Brasil e sua variabilidade. Revista Brasileira de Meteorologia, v. 21, n. 2, p. 271282, 2006.

DARKWA, K.; AMBACHEW, D.; MOHAMMED, H.; ASFAW, A.; BLAIR, M. W. Evaluation of common bean (Phaseolus vulgaris L.) genotypes for drought stress adaptation in Ethiopia. The crop Journal, v. 4, n. 5, p. 367-376, 2016.

DARELA-FILHO, J.; LAPOLA, D.; RODRIGUES TORRES, R.; LEMOS, M. Socioclimatic hotspots in Brazil: how do changes driven by the new set of IPCC climatic projections affect their relevance for policy? Climatic Change, v. 136, n. 4, p. 24-34, 2016. 
DOORENBOS, J.; KASSAM, A.H. Yield response to water. Rome: FAO. Irrigation and Drainage Paper, v. 33, 193p, 1979.

FAGUNDES, J. D.; De PAULA, G. M.; LAGO, I.; STRECK, N. A.; BISOGNIN, D. A. Aquecimento global: efeitos no crescimento, no desenvolvimento $\mathrm{e}$ na produtividade da batata. Ciência Rural, v. 40, p. 1464-1472, 2010a.

FAGUNDES, J.D.; STRECK, N.A.; BISOGNIN, D.A.; SCHWANTES, A.P.; ALBERTO, C.M. Produtividade simulada de tubérculos de batata em cenários de mudanças climáticas. Pesquisa Agropecuária Brasileira, v.45, n.4, p. 351-360, 2010b.

FLAUZINO, B. K.; MELLONI, E.G.P.; PONS, N.A.D.. LIMA, O. Mapeamento da capacidade de uso da terra como contribuição ao planejamento de uso do solo em sub-bacia hidrográfica piloto no sul de Minas Gerais. Geociências, v.35, n.2, p.277-287, 2016.

FLORÊNCIO, G.W.L.; MARTINS, F.B.; FERREIRA, M.C.; PEREIRA, R.A.A. Impacts of climatic change on the vegetative development of olive cultivars. Revista Brasileira de Engenharia Agrícola e Ambiental, v. 23, n.9, p.77-82, 2019.

GIORGI, F.; JONES, C.; ASRAR, G, R. Addressing climate information needs at the regional level: the CORDEX framework. World Meteorological Organization Bulletin, v. 58, p. 175-183, 2009.

HEINEMANN, A. B.; STONE, L. F.; SILVA, S. C. Feijão. Em: MONTEIRO, J. E. In: Agrometeorologia dos cultivos: o fator meteorológico na produção agrícola. INMET, Brasília, p. 182-201, 2009.

HEINEMANN, A.B.; RAMIREZ-VILLEGAS, J.; SOUZA, T.L.P.O.; DIDONET, A.D.; DI STEFANO, J.G.; BOOTE, K.J.; JARVIS, A. Drought impact on rainfed common bean production areas in Brazil. Agricultural and Forest Meteorology, v. 225, p.57-74, 2016.

HEINEMANN, A.B.; RAMIREZ-VILLEGAS, J.; STONE, L.F.; DIDONET, A.D. Climate change determined drought stress profiles in rainfed common bean production systems in brazil. Agricultural and Forest Meteorology, v. 246, p. 6477, 2017.

IBGE - Instituto Brasileira de Geografia e Estatística. Rio de Janeiro. 2019. Disponível em <https://cidades.ibge.gov.br/brasil/mg/itajuba>. Acesso em: 26 de setembro de 2019.

IBGE - Instituto Brasileiro De Geografia e Estatística. Pesquisa mensal de previsão e acompanhamento das safras agrícolas no ano civil. Levantamento sistemático da produção agrícola, Rio de Janeiro, v. 30, n.6, p.1-83, 2017.

IPCC. Intergovernmental Panel on Climate Change - Summary for Policymaker. In: STOCKER, T. F.; QIN, D.; PLATTNER, G. K.; TIGNOR, M.; ALLEN, S. K.; BOSCHUNG, J.; NAUELS, A.; XIA, Y.; BEX, V.; MIDGLEY, P. M. (Eds). Climate Change 2013: The Physical Science Basis. Contribution of Working Group I to the Fifth Assessment Report of the Intergovernmental Panel on Climate Change. Cambridge University Press, Cambridge, United Kingdom and New York, NY, USA, 2013.

IPEA. A década inclusiva (2001-2011): desigualdade, pobreza e políticas de renda. Rio de Janeiro: IPEA, 2012. (Comunicado do Ipea, n. 155). 
JERSZURKI, D.; SOUZA, J.L.M.; ADAMUCHIO, J.G. Funções de estimativa do armazenamento de água no solo sob diferentes níveis de capacidade de água disponível. Revista Brasileira de Ciências Agrárias, v. 13, n. 3, e.5552, 2018.

LEMOS FILHO, L. C. A.; CARVALHO, L. G.; EVANGELISTA, A. W. P.; ALVES JÚNIOR, J. Análise espacial da influência dos elementos meteorológicos sobre a evapotranspiração de referência em Minas Gerais. Revista Brasileira de Engenharia Agrícola e Ambiental, v. 14, n.12, p. 1294-1303, 2010.

LIMA, O. Distribuição de solos em catenas e mapeamento pedológico de subbacia hidrográfica piloto na região de Itajubá. Itajubá, 2012, 139 f. Dissertação. (Mestrado em Meio Ambiente e Recursos Hídricos), Universidade Federal de Itajubá.

LLOPART, M.; ROCHA, R. P. da.; REBOITA, M. S.; CUADRA, S. Sensitivity of simulated South America climate to the land surface schemes in RegCM4. Climate Dynamics, v. 49, n.11, p. 3975-3987, 2017.

MAPA - Ministério da Agricultura, Pecuária e Abastecimento. Portaria 55/2019. Brasília. 2019. Disponível em <http://www.in.gov.br/web/dou/-/portaria-n-55de-1-de-julho-de-2019-191918853>. Acesso em: 26 de setembro de 2019.

MARENCO, R.A.; LOPES, N.F. Fisiologia vegetal: fotossíntese, respiração, relações hídricas e nutrição mineral. Universidade Federal de Viçosa, 2009. 436p

MARTINS, F. B.; GONZAGA, G.; SANTOS, D. F.; REBOITA, M. S. Classificação Climática De Köppen E De Thornthwaite Para Minas Gerais: Cenário Atual e Projeções Futuras. Revista Brasileira de Climatologia, v.14, p. 129-156, 2018.

MARTINS, F. B.; PEREIRA, R. A. A; PINHEIRO, M. V.; ABREU, M. C. Desenvolvimento foliar em duas cultivares de oliveira estimado por duas categorias de modelos. Revista Brasileira de Meteorologia, v.29, n.4, p. 505 $514,2014$.

MARTINS, M. A.; TOMASSELA, J.; DIAS, C. G. Maize yield under a changing climate in the Brazilian Northeast: Impacts and adaptation. Agricultural Water Management, v.216, p.339-350, 2019.

MATHOBO, R.; MARAIS, D.; STEYN, J. M. The effect of drought stress on yield, leaf gaseous exchange and chlorophyll fluorescence of dry beans (Phaseolus vulgaris L.). Agricultural Water Management, v. 180, p. 118-125, 2017.

MENEZES, C.B. PINTO, C.A.B.P.; NURMBERG, P.L.; LAMBERT, E.S. Avaliação de genótipos de batata (Solanum tuberosum L.) nas safras das águas e inverno no sul de Minas Gerais. Ciência e Agrotecnologia, v.23, n.4, p. 776-783, 1999.

MOSS, R. H.; EDMONDS, J. A.; HIBBARD, K. A.; MANNING, M. R.; ROSE, S. K.; VAN VUUREN, D. P.; CARTER, T. R.; EMORI, S.; KAINUMA, M.; KRAM, T; MEEHL, G. A.; Mitchell, J. F. B.; NAKICENOVIC, N.; RIAHI, K.; SMITH, S. J.; STOUFFER, R. J.; THOMSON, A.; WEYANT, J. P.; WILLBANKS, T. J. The next generation of scenarios for climate change research and assessment. Nature, v.463, p.747-756, 2010.

NATIVIDADE, U. A.; GARCIA, S. R.; TORRES, R. R. Tendência dos Índices de Extremos Climáticos Observados e Projetados no Estado de Minas Gerais. Revista Brasileira de Meteorologia, v. 32, p. 600-614, 2017. 
OLIVEIRA, M.G.C.; OLIVEIRA, L.F.C.; WENDLAND, A.; GUIMARÃES, C. M.; QUINTELA, E. D.; BARBOSA, F. R.; CARVALHO, M. da C. S.; LOBO JUNIOR, M.; SILVEIRA, P. M. da. Conhecendo a fenologia do feijoeiro e seus aspectos fitotécnicos. EMBRAPA: Brasília, 2018. 62p.

PEREIRA, A. R.; ANGELOCCI, L. R.; SENTELHAS, P. C. Meteorologia Agrícola. Piracicaba, 2007. 192p.

PEREIRA, A. R. Simplificando O Balanço Hídrico de Thornthwaite. Bragantia, v.64, n.2, p.311-313, 2005.

PORFIRIO, L. L.; NEWTH, D.; FINNIGAN, J. J.; CAI, Y. Economic shifts in agricultural production and trade due to climate change. Palgrave Communications, v.4, p. 111-125, 2018.

RAMIREZ-CABRAL, N. Y. Z.; KUMAR, L.; SHABANI, F. Global alterations in areas of suitability for maize production from climate change and using a mechanistic species distribution model (CLIMEX). Scientific Reports, v.7, p. 1-13, 2017.

REBOITA, M. S.; MARRAFON, V. H. A.; LLOPART, M.; DA ROCHA, R. P. Cenários de mudanças climáticas projetadas para o estado de Minas Gerais. Revista Brasileira de Meteorologia, v. 33, n. 2, p. 207-224, 2018a.

REBOITA, M. S.; DIAS, C. G.; DUTRA, L. M.; DA ROCHA; R. P.; LLOPART, M. Previsão climática sazonal para o Brasil obtida através de modelos climáticos globais e regional. Revista Brasileira de Meteorologia, v. 33, n. 2, p. 207-224, 2018b.

REBOITA, M.S.; SILVA, B.C. da; SILVA, M.V.da. Modelos de regressão aplicados à previsão de nível fluviométrico no Sio Sapucaí em Itajubá-MG. Anuário do Instituto de Geosciências, v. 42, n.2, p. 217-229, 2019.

RESENDE, N. C.; MIRANDA, J. H.; COOKE, R.; CHU, M. L.; CHOU, S. C. Impacts of regional climate change on the runoff and root water uptake in corn crops in Parana, Brazil. Agricultural Water Management, v.221, p. 556-565, 2019.

SANTOS, D. F. dos; MARTINS, F.B.; TORRES, R.R. Impacts of climate projections on water balance and implications on olive crop in Minas Gerais. Revista Brasileira de Engenharia Agrícola e Ambiental, v. 21, n. 2, p. 77 - 82, 2017.

SANTOS, L. F.; MARTINS, F. B.; GARCIA, S. R. Padrões climatológicos de precipitação e temperatura do ar associados ao rendimento do feijão comum em Minas Gerais. Revista Brasileira de Climatologia, v. 14, p.3-24, 2018.

SEDIYAMA, G.C.; MELO JUNIOR, J.C.; SANTOS, A.R.; RIBEIRO, A.; COSTA, M.H.; HAMAKAWA, P.J.; COSTA, J.M.N.; COSTA, L.C. Zoneamento agroclimático do cafeeiro (Coffea arabica L.) para o Estado de Minas Gerais. Revista Brasileira de Agrometeorologia, v.9, p.501-509, 2001.

SENTELHAS, P.C.; SANTOS, D.L. dos; MACHADO, R.E. Water deficit and water surplus maps for Brazil, based on FAO Penman Monteith potential evapotranspiration. Revista Ambiente e Água, v. 3, p. 28 42, 2008.

SIDRA - Sistema IBGE de Recuperação Automática. Rio de Janeiro. 2019. Disponível em: <(https://sidra.ibge.gov.br/Tabela/1612\#resultado)> Acesso em: 24 de setembro de 2019. 
SILVA, E. D.; REBOITA, M. S. Estudo da Precipitação no Estado de Minas Gerais - MG. Revista Brasileira de Climatologia, v. 13, p. 120-136, 2013.

SLAMA, F.; ZEMNI, N.; BOUKSILA, F. Modelling the Impact on Root Water Uptake and Solute Return Flow of Different Drip Irrigation Regimes with Brackish Water. Water, v. 11, p. 1-17, 2019.

TANASIJEVIC, L.; TODOROVIC, M.; PEREIRA, L. S.; PIZZIGALLI, C.; LIONELLO, $P$. Impacts of climate change on live crop evapotranspiration and irrigation requirements in the Mediterranean region. Agricultural Water Management, v.144, p. 54-68, 2014.

TAVARES, P. S.; GIAROLlA, A.; SILVA, A. J. P.; LYRA, A. A.; CHOU, S. C. Climate change impact on the potential yield of Arabica coffee in southeast Brazil. Regional Environmental Change, v.18, p. 873-883, 2018.

THORNTHWAITE, C.W.; WILM, H.G. Report of the Commite on evapotranspiration and transpiration, 1943-1944. Washington, D.C.: Transactions of the American Geophysical Union, p.686-693, 1944.

THORNTHWAITE, C.W. An approach toward a rational classification of climate. Geographical Review, New York, v.38, n.1, p.55-94, 1948.

THORNTHWAITE, C.W.; MATHER, J.R. Instructions and tables for computing potential evapotranspiration and water balance. Centerton: Drexel Institute of Technology - Laboratory of Climatology, 1957. 311p.

THORNTHWAITE, C.W.; MATHER, J.R. The Water Balance. Centerton, N.J.: Drexel Institute of Technology - Laboratory of Climatology, 104p. 1955. Publications in Climatology, v.8, n.1.

WORLD METEOROLOGICAL ORGANIZATION. Calculation of monthly and annual 30-year standard normals. Geneva, 1989. Technical document, n. 341; WCDP, n. 10

ZANON, A. L.; STRECK, N. A.; DA SILVA, M. R.; BISOGNIN, D. A. Desenvolvimento das plantas e produtividade de tubérculos de batata em clima subtropical. Revista Ciência Agronômica, v. 44, n. 4, p. 858-868, 2013 